\title{
Flexible Learning in an Information Society
}

\author{
Edited by Badrul H. Khan \\ Information Science Publishing, 2006 \\ pp.354, ISBN: 1599043262
}

\author{
Reviewed by Dr. Adile Aşkım Kurt \\ Faculy of Education \\ Anadolu University \\ Eskisehir-TURKEY
}

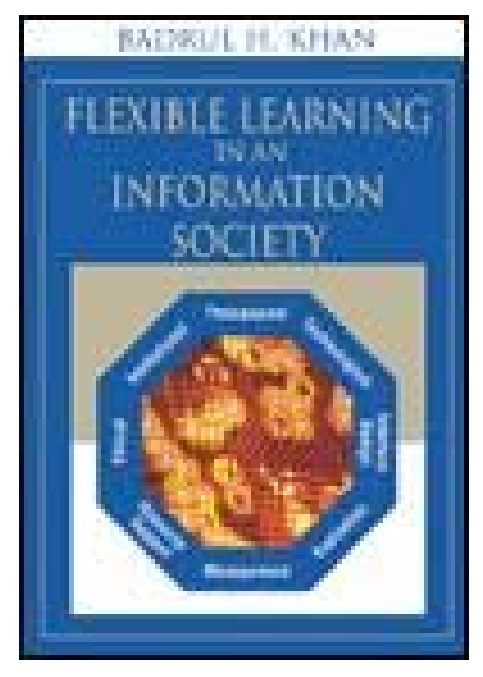

This book was edited by, Badrul H. Khan, Director of the Educational Technology Leadership graduate cohort program at The George Washington University, and published by Information Science Publishing an imprint of Idea Group Inc.

The information age has brought about many ways for educators to help their students learn, creating an atmosphere where the learners desire flexibility in the way they learn. With the increasing use of variety of approaches for learning, students' preferences are changing from wanting to be taught mostly in lectures or direct training sessions to wanting increased flexibility. Students expect on demand anytime/anywhere highquality learning environments with good support services. They want increased flexibility.

This book uses a flexible learning framework to create meaningful flexible learning environments. This framework consists of eight factors; institutional, management, technological, pedagogical, ethical, interface design, resource support, and evaluation. This book presents a broad understanding of the emerging field of flexible learning and provides guidance in creating these environments. The book has thirty chapters, encompass various critical issues dealing with one or more categories of the flexible learning framework and offer a variety of points of view on these issues.

\section{CONTENTS OF THE BOOK}

Foreword

Preface

Chapter 1: Flexible Learning in an Open and Distributed Environment, Badrul H. Khan, argues the importance of increased flexibility in learning, introduce a Framework for Flexible Learning.

Chapter 2: Modes of Openness and Flexibility in Cognitive Flexibility Hypertext Learning Environments, Rand J. Spiro, Brian P. Collins, Aparna R. Ramchandran, talk about characteristics of cognitive flexibility hypertext learning environments. 
Chapter 3: Authentic learning on the Web: Guidelines for Course Design, Jan Herrington, Ron Oliver, Anthony Herrington, propose nine critical characteristics of learning as a framework for the design of more authentic learning environments on the Web.

Chapter 4: Designing Community Learning in Web-Based Environments, Mercedes Fisher, Bonita Coleman, Paul Sparks, Cherly Plett, review several strategies for creating effective collaboration and community in online environments.

Chapter 5: Intercultural Collaborative Project-Based Learning in Online Environments, Karen L. Murphy, Yakut Gazi, Lauren Cifuentes, present a model for a polycentric culture that minimize differences among individuals in terms of their worldviews, communication practices, and technological issues.

Chapter 6: We'll Leave the Light On For You: Keeping Learners Motivated in Online Courses, Vanessa Paz Dennen, Curtis J. Bonk, focus on ten key elements for motivating online learners.

Chapter 7: Humanizing Learning-at-Distance: Best Practice Guidelines for Synchronous Instructors, Kathleen Barclay, presents a set of guidelines that raises awareness of best practices that novice and seasoned synchronous instructors may use to foster successful live online learning environments.

Chapter 8: Storytelling as a Web-Based Workplace Learning Pedagogy, Nick Nissley, describes the evolution of storytelling in the workplace.

Chapter 9: Use Of Virtual Exhibits For Promoting Informal Science Learning On The Webs Of Science Centers, Leo Tan Wee Hin, R. Subramaniam, discuss how virtual exhibits provide useful instructional support for exploring scientific concepts through inquiry.

Chapter 10: Flexible Learning - On-Site!, Claus Witfelt, takes a different approach to flexible learning and how technologies from distributed, flexible learning can be used in everyday university teaching and learning.

Chapter 11: Asynchronous Content Design for Flexible Learning: The Macro and Micro Level of Frameworks to Share Knowledge Online between Professionals and Community, Gülsün Kurubacak, T.Volkan Yüzer, discuss design principles, ethics, and pitfalls of asynchronous content in e-learning systems.

Chapter 12: Online Faculty Proficiency and Peer Coaching, Jason D. Baker, Shana Tonkin, share a case study of peer observation and coaching activities in an institution. The peer coaching cycle used consists of three stages: planning conference, instructional observation, and a reflecting conference.

Chapter 13: What do they Learn?, Carla R. Payne, stresses the results of transcript analysis can be a useful tool for achieving greater teaching effectiveness. 
Chapter 14: Mobile Learning Technologies, Diane M. Gayeski, explains the need and significance of mobile technologies in flexible learning.

Chapter 15: Strategies for Sharing the ReMoTe: Changing the Nature of Online Collaboration, Richard Caladine, Brian Yecies, discuss the delivery and evaluation of ReMoTe, a Web-based virtual group workspace that facilities learning activities between learners at a distance.

Chapter 16: Integrating Multimedia Cues in E-Learning Documents for Enhanced Learning, Ankush Mittal, Krishnan V. Pagalthivarthi, Edward Altman, present a user-centric approach to a learning where students can organize, analyze, share, and discuss their insights, experiments, and results more easily and in a more effective manner.

Chapter 17: Interface Design for Web Learning, Lorna Uden, discusses the Web user object modeling method to guide designers to develop Web learning applications that have high usability.

Chapter 18: Improving the Usability of Distance Learning Through Template Modification, Linda L. Lohr, David A. Falvo, Erin Hunt, Ben Johnson, examine the interactions of instructors and students with a widely used distance learning authoring system.

Chapter 19: Management of the Learning Space, Susan M. Powers, Christine Salmon, discuss workload management, student management, and time management as three principal issues involved in effective learning space management.

Chapter 20: Ethical Issues in Web-Based Learning, Joan D. McMahon, tackles the important issue of ethical issues that arise with online education.

Chapter 21: Moving Towards the Implementation of Contextualized Educational Technology, Esko Kahkönen, Erkki Sutinen, discuss key areas in the implementation of contextualization, including dialogical learning, community building, and the concept of "ethonocomputing".

Chapter 22: Evaluation Strategies for Open and Distributed Learning Environment, Thomas C. Reeves, John G. Hedberg, present a pragmatic philosophy of evaluation.

Chapter 23: Components of Effective Evaluation in Online Learning Environments, Steven $\mathbf{R}$. Terrell, provides a model to address the notion that evaluation and assessment should be included as an integral, ongoing part of an online management system.

Chapter 24: Flexible assessment: Some Tensions and Solutions, Chris Morgan, Jenny Bird, argue that flexible teaching and assessment methods offer some alternatives for teachers and students 
Chapter 25: Toward a Comprehensive Model of E-Learning Evaluation: The Components, Curtis J. Bonk, Robert A.Wisher, Matthew V. Champagne, provide eight evaluation considerations that can assist in understanding the impact and effectiveness of an e-learning effort.

Chapter 26: Evaluating Flexible Learning in Terms of Course Quality, Betty Collis, Anoush Margaryan, present a model or evaluating the quality of blended courses in the corporate setting.

Chapter 27: Assessing Online Collaborative Learning: A Theory, Methodology and ToolSet, Linda Harasim, focuses on the unique opportunities whereby instructors, educators, researches, and students can analyze and assess learning.

Chapter 28: Evaluating the Flexibility of Learning Processes in e-Learning Environments, Maia T. Dimitrova, describes the three main dimensionslocation, time, and method flexibility- of flexible learning in online learning environments.

Chapter 29: Obstacles Encountered by Learners, Instructors, Technical Support and Librarians, Badrul H. Khan, Laura J. Cataldo, Ruth Bennett, Salvatore Paratore, present a compilation of major obstacles encountered by learners, instructors, technical support, and librarians during online learning.

Chapter 30: A Program Satisfaction Survey Instrument for Online Students, Henry L. Smith, Badrul H. Khan, use a program evaluation survey based on the eight dimensions of the flexible learning framework to understand the attitudes of online education students. 